\title{
O papel da escola nas unidades de internação de jovens, segundo os atores
}

\section{The role of school in internal units, with the actors}

\author{
Washington Luís de Andrade Cardoso Junior ${ }^{1}$ \\ Maria Couto Cunha ${ }^{2}$
}

\section{Resumo}

Este artigo é o recorte de uma pesquisa de mestrado de inspiração marxista, tendo como referenciais teóricos os conceitos de hegemonia de Gramsci (1968), de Aparelhos Ideológicos do Estado de Althusser (1985) e a docilidade dos corpos de Foucault (1999). Seu objetivo foi analisar as percepções do papel da escolarização para os sujeitos inseridos em duas Comunidades de Atendimento Socioeducativo de Internação a partir da análise de 13 (treze) entrevistas semiestruturadas contemplando quatro segmentos inseridos na educação formal dos adolescentes internados: gerentes, diretores, professoras, alunos; e socioeducadores. Os resultados levaram a considerar que institucionalização dos mecanismos do poder disciplinar sobre os corpos e as normas das Unidades de Internação limitam experiências de democracia e participação dos sujeitos nas decisões, ao passo que a escolarização é identificada como principal diferença entre os espaços prisionais e as unidades de atendimento socioeducativo.

Palavras-Chave: Socioeducativo; Direito a Educação; Privação de Liberdade.

\begin{abstract}
This article is the excerpt of a master's research of Marxist inspiration, having as theoretical references the concepts of hegemony of Gramsci (1968), of Ideological Apparatus of the State of Althusser (1985) and the docility of the bodies of Foucault (1999). Its objective was to analyze the perceptions of the role of schooling for the subjects inserted in two Juvenile Detention Centers from the analysis of 13 (thirteen) semi-structured interviews covering four segments inserted in the formal education of the hospitalized adolescents: managers, directors, teachers, students; and socio-educators. The results led to consider that the institutionalization of the mechanisms of disciplinary power over the bodies and the rules of the Inpatient Units limit experiences of democracy and the participation of subjects in decisions, whereas schooling is identified as the main difference between prison spaces and units socio-educational assistance

\footnotetext{
1 Doutorando em Educação- Universidade Federal da Bahia-UFBA; pesquisador vinculado à linha a Linha de Pesquisa em Política e Gestão da Educação do PPGE(UFBA). orcid: https://orcid.org/0000-0003-10202733. email xitaodabahia85@outlook.com

${ }^{2}$ Professora do Programa de Pós-Graduação em Educação; pesquisadora vinculada à linha a Linha de Pesquisa em Política e Gestão da Educação do PPGE-Universidade Federal da Bahia (UFBA).orcid: http://orcid.org/0000-0002-2081-7232. Email: mariacoutocunha@gmail.com
} 
Keywords: Socio-educational. Right to education. Deprivation of freedom

\section{Introdução}

A Constituição Federal Brasileira(CF) de 1988, no seu artigo 227, estabelece crianças e adolescentes como sujeitos de direitos e impõe uma lógica constitucional que não recepciona as concepções menoristas. O que leva a uma ampla mobilização popular para a revogação do Código de Menores de 1979 e à construção de um dispositivo legal pautado no paradigma da garantia de direitos, que estabelecesse a responsabilização e a sanção como premissa da intervenção estatal sobre a infância e a adolescência. Nesses termos, a partir da responsabilização penal aos maiores de dezoito anos, prescrita no artigo 228 da Constituição Federal, é construído o Estatuto da Criança e do Adolescente (ECA) com mudanças importantes no tratamento/tutela dos/das “jovens em conflito com a lei”.

A perspectiva anunciada no texto do ECA aponta para um projeto de superação das concepções de criminalização das juventudes pautada nas concepções menoristas. Apesar dos avanços importantes na defesa dos direitos dos adolescentes autores de atos infracionais, Rizzini, Sposati e Oliveira (2019) apontam limites claros na ruptura com o projeto de controle social penal sobre as juventudes negras/pauperizadas sistematizados nos Códigos de Menores de 1927 e 1978, no que se trata de representações e práticas criminalizantes (RIZZINO; SPOSATI; OLIVEIRA, 2019).

Distante do senso comum que atribui ao ECA uma licença para a juventude transgredir os comportamentos descritos no código penal e abraçar a criminalidade, esse Estatuto estabelece padrões de responsabilização dos adolescentes referenciados em três princípios: brevidade, excepcionalidade e o das condições especiais de pessoa em desenvolvimento. Esses princípios, que se interligam, definem uma nova proposta educativa que privilegia a fase da adolescência, considerando o tempo limitado da ação educativa e a condição peculiar de desenvolvimento do educando (VOLPI, 1999).

Em convergência ao prescrito pela $\mathrm{CF}$ que considera a criança e o adolescente como sujeitos de direitos, o ECA associa as medidas socioeducativas à lógica da proteção integral como a presunção da inocência, a ampla defesa e o princípio do contraditório (OLIVEIRA; 
VALENTE, 2017, p.41). Como consequência disso o ECA prescreve duas exigências complementares e interdependentes no atendimento socioeducativo: sanção e responsabilização.

Como desdobramento da relação dialética dos princípios da sanção e responsabilização previstos no marco legal, a educação cumpre um papel central nas formulações relacionadas ao atendimento socioeducativo. Não por acaso, a expressão "socioeducação" é corrente nos documentos oficiais dos estabelecimentos de acolhimento institucional de "adolescentes em conflito com a lei", incluindo os casos de atos infracionais considerados graves, onde esses jovens são submetidos à tutela do Estado em Unidades de Internação. Craidy (2017) aponta a relação entre a socioeducação e a educação a partir da necessária ação educativa sobre crianças e adolescentes articulada com a sua realidade concreta: comunidade de origem; família; escola e outros espaços de sociabilidade.

Esta concepção de Educação de sujeitos que têm direito à palavra é indispensável para que se compreenda a relação entre socioeducação e educação. Melhor seria dizer que socioeducação é educação. Por que então acrescentar o prefixo sócio à educação? Porque se destina a adolescentes que tiveram sua educação social prejudicada em alguns dos ambientes ou em vários em que viveram ou vivem, que podem ser a comunidade de origem; a família; a escola, e outras, entrelaçadas numa macroestrutura social opressiva. É preciso ajudar a recompor o que lhes foi negado. Daí ser impossível socioeducar sem trabalhar junto com a família e com a escola, principais espaços educacionais. (CRAIDY, 2017, pp 85-86)

A CF, o ECA e a Lei que instituiu o Sistema Nacional de Medidas Socioeducativas (SINASE) representam a materialização do Sistema de Garantia de Direitos (SGD) para as crianças e adolescentes "em conflito com a lei", ao demarcarem um padrão de responsabilização condizente com sua condição peculiar de desenvolvimento. A elevação do SINASE à condição de um diploma legal aponta contornos para elementos anunciados pela Ordem Constitucional de 1988, mas que careciam de regulamentação. Com a promulgação da Lei $n^{0} 12594 / 2012$ abre a possibilidade para a luta pelo direito à educação desses sujeitos a que tantos direitos foram negados. 


\section{Desenvolvimento da pesquisa}

A ação socioeducativa e seus princípios norteadores (sanção e responsabilização) previstos no marco legal partem de uma perspectiva filosófica restaurativa no que pese uma distância aparente entre o "anunciado e o praticado". A pesquisa se desenvolveu em duas Escolas do Sistema Municipal de Ensino de Salvador, localizadas em duas Comunidades de Atendimento Socioeducativo de Internação mantidas pelo Governo de Estado da Bahia.

O trabalho é inspirado na compreensão materialista-histórica e dialética da realidade. Esse caminho interpretativo busca analisar a realidade a partir de um ponto material, conformado historicamente e entrelaçado de contradições. Isso converge para o uso complementar da abordagem gramsciana, em especial, a construção do consenso/coerção como forma da Sociedade Política (Estado) se relacionar com a Sociedade Civil. Essa inspiração carrega uma convergência com elementos tradicionalmente distantes da tradição marxista, como a caracterização dos dispositivos de controle dos corpos, "os corpos dóceis", da obra Vigiar e Punir de Michel Foucault em paralelo com a formulação de Louis Althusser sobre as escolas e as prisões como Aparelhos Ideológicos do Estado.

O trabalho de coleta de dados foi pautado por treze entrevistas semiestruturadas, contemplando representantes dos segmentos envolvidos na educação formal de duas escolas, a partir de uma abordagem qualitativa. Para sistematizar as informações, adotamos a técnica de análise de conteúdo, a partir da perspectiva teórica de Bardin (2016). Para a caracterização e sondagem previa, os treze sujeitos responderam questionários adequados ao seu segmento.

A escolha dos profissionais levou em consideração o tempo de atuação no socioeducativo e nas duas unidades de internação ${ }^{3}$. O uso dos questionários como forma de caraterização dos sujeitos trouxe à tona não apenas informações relacionadas ao itinerário profissional e aspectos socioeconômicos, mas elementos que ajudam a compreender o(s) sentido(s) assumido(s) nas falas dos/das participantes das entrevistas para além dos discursos

\footnotetext{
${ }^{3}$ Para garantir a confidencialidade dos/as colaboradores/as da pesquisa os registros das suas falas foram feitos mediante um único gênero. Dessa maneira a partir desse ponto as profissionais do segmento magistério serão chamadas de professoras 01,02 e 03 , com os servidores que ocupam os cargos de direção escolar serão mencionados como diretor 01 e 02 .
} 
institucionais. Desse modo, mesmo que o ordenamento jurídico não anuncie os estabelecimentos educacionais responsáveis pelo cumprimento das medidas socioeducativas de internação como espaços prisionais, a realidade expressa no imaginário social é (re)produzida pelos atores engajados na tutela desses jovens. A fala de um aluno também mostra essa reprodução.

A minha opinião sobre a escola é que independentemente de a gente estar no privado, para mim a mesma aula que dá aqui, eles dão lá fora, não vejo diferença é o mesmo tratamento [...] (ALUNO3).

A esse respeito é emblemática a fala do aluno3, pois expressa a convergência simbiótica dessas duas dimensões do Aparelho de Estado: repressiva (força) e ideológica (consenso). Althusser (1985) ao descrever de maneira esquemática os Aparelhos de Estado em ideológicos e repressivos, demarca que todo aparelho repressivo prescinde de mecanismos ideológicos para justificar sua existência, bem como os aparelhos ideológicos demandam o uso da repressão para manter sua coesão social.

Ao descrever a realidade escolar, a fala do aluno3 marca a privação de liberdade como o ponto de partida da sua descrição. Logo, apesar do marco legal anunciar o caráter não prisional desses estabelecimentos educacionais, a realidade concreta e a vivência desses sujeitos nos leva a considerar a privação de liberdade como elemento estratégico na análise das entrevistas.

A esse respeito é importante contextualizar as engrenagens penais seletivas (BORGES, 2018; DAVIS, 2018; e FLAUZINA, 2017) como ponto de partida da exclusão ou morte social conformada na privação de liberdade (encarceramento/internação). Sobre isso, Borges (2018) aponta um quadro de super-representação dos negros/as na população carcerária e sua presença minoritária entre os/as agentes do Estado engajados na prestação jurisdicional, o que converge com os dados do levantamento anual do SINASE, onde um Sistema de Justiça - masculino, branco e privilegiado - julga e estabelece a dosimetria das penas e/ou medidas socioeducativa de internação para os “indesejáveis” (negros/pobres).

A super-representação nos espaços de privação de liberdade é um reflexo de mecanismos estruturais de negação de direitos e manutenção de desigualdades. A esse respeito os dados do IBGE, referentes ao ano de 2016, convergem para esta análise quando 
apontam um percentual de $15 \%$ de jovens entre 15 e 17 anos que estão fora da escola ou dos $14,1 \%$ que têm a obrigação de conciliar os estudos com atividades laborais.

O levantamento do Atlas da Violência de 2019 no que tange às juventudes mostra a exposição desse segmento plural a um risco de letalidade, que converge para a ideia defendida por Flauzina (2017) do genocídio como um projeto histórico de longa duração do Estado brasileiro com a população negra. Segundo esta autora, a confluência de condições que impedem o acesso e/ou permanência na educação formal e o padrão de violência letal sobre esse contingente populacional, impõem a esses sujeitos uma realidade que levava $23 \%$ desses jovens a não estarem nem estudando, nem trabalhando em 2017. Logo, caracterizar os sujeitos da pesquisa - como espelho ilustrativo da realidade estudada - passa por conformar a relação dialética entre os projetos educativos enunciados e as concepções criminalizantes, ou não, expressas nos depoimentos.

O acesso às duas unidades de internação para a coleta de dados, sob a autorização expressa das instituições coparticipantes (FUNDAC e SMED), confirmou aspectos relacionados à estrutura física e a dinâmica aparente de funcionamento das $\mathrm{CASEs}^{4}$. Enquanto na CASE-02, construída após a vigência do ECA os/as profissionais demonstravam uma maior familiaridade com as ferramentas (notebook, caderno de campo e celular) para o registro das entrevistas, na CASE-01, espaço projetado sob a arquitetura institucional do Código de Menores, seguiu uma sequência de procedimentos administrativos para validar os instrumentos de coleta de dados já expostos na solicitação de anuência institucional. Assim, a CASE-02 aparenta um ambiente mais próximo do apontado pelo marco legal instituído pelo ECA e, portanto, com uma rotina administrativa mais acolhedora para o desenvolvimento de pesquisas de campo.

O quadro geral das falas dos/das profissionais apresentam uma vinculação discursiva com o Sistema de Garantia de Direitos (SGD) estabelecido a partir do SINASE, utilizando expressões próprias do marco legal instituído pelo ECA. Os/as entrevistados(as) se referem à Escola como o ponto central do atendimento socioeducativo, em conjunto com os diversos

\footnotetext{
${ }^{4}$ Para garantir a confidencialidade dos informantes e o cumprimento dos compromissos da ética nas pesquisas com seres humanos as Unidades de Internação serão denominadas CASE 01 e CASE 02.
} 


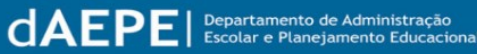

setores da Unidade.

\section{A importância da escola no contexto do socioeducativo}

O enquadramento da(s) fala(s) no horizonte anunciado pelo SGD aponta a existência da Escola (dimensão pedagógica) como principal diferencial entre as unidades de internação e os espaços prisionais. No entanto, mesmo com os avanços instituídos com a Ordem Constitucional de 1988 (ECA e SINASE), são evidentes os mecanismos de criminalização/estigmatização que persistem no marco legal vigente (OLIVEIRA; VALENTE, 2017; RIZZINO; SPOSATI; OLIVEIRA, 2019) materializadas nas falas que pontuam o evidente caráter da privação de liberdade nas medidas socioeducativas de internação.

Se não houvesse escola nós estaríamos aqui com pessoas privadas de liberdade e sem o contato com o instrumento de transformação humana, que é a educação, sem escola não seriamos socioeducação. Seríamos qualquer coisa, provavelmente um presídio. A escola é de fundamental importância para existir nossa socioeducação. (GERENTE 01)

É justamente não podar a vida social do indivíduo que está cumprindo a medida socioeducativa, já que ele não está em liberdade a escola oferece que eles deem continuidade a sua vida social no que diz respeito ao ensino didático, preservando o direito à educação... (SOCIOEDUCADOR 02).

A persistência da concepção menorista na contramão dos princípios anunciados no marco legal em vigor tem sintonia com a afirmação de Gontijo (2019).

a maioridade penal já existe nas práticas observadas junto aos adolescentes, encarcerados em função de atos infracionais, mas sem a possibilidade de reintegração social, finalizada a medida, com vistas à construção de uma outra trajetória de vida. (GONTIJO, 2019, p.85)

Em contraposição as permanências perversas de mecanismos de criminalização das juventudes pauperizadas (negras/periféricas), os informantes demarcam a educação formal (escolarização) como ponto central da medida socioeducativa indo ao encontro das premissas legais instituídas no ECA e no SINASE. A escola é apontada como grande diferencial entre a internação e o encarceramento. 


\section{Articulação institucional e pedagógica}

As falas dos dois gerentes anunciam uma relação institucional colaborativa com canais de diálogo entre a Gerência das Unidades e a Direção das duas escolas. No decorrer das entrevistas foi possível perceber que os informantes pautaram suas respostas na estrutura administrativa das CASEs como ponto de partida das suas falas, o que expõe a pesquisa ao desafio de criar caminhos explicativos de romper as armadilhas do discurso institucional projetado nas palavras desses profissionais.

Nós temos um canal aberto. Normalmente trato diretamente com o diretor da escola. É incomum eu tratar com qualquer professor ou profissional, sem antes tratar com o diretor. É ele que conhece sua equipe, é ele que tem essa gestão. É importante salientar que mesmo tendo essa relação direta com o diretor, temos uma equipe destinada a atenção à escola, ligada ao setor pedagógico, a questão documental, a questão do comportamento do adolescente, o suporte psicossocial ao adolescente, a relação com os familiares. Todos os aspectos vinculados a institucionalização desse sujeito. (GERENTE 01)

(...)

[...]Gerir pessoas não é brincadeira, a gente tem que gerir os egos, as vaidades, os títulos, mas eu tenho uma relação muito boa com o corpo docente. É uma interação muito boa com os professores e a gestão, com o corpo docente e a equipe técnica. Alguns atritos são normais, mas no final tudo dá certo e a gente consegue ter um bom diálogo entre as duas equipes. (GERENTE 02)

No entanto a intervenção desse gerente, conforme sua fala, para mediar uma situação concreta de conflito entre uma professora e um aluno apresenta elementos para compreender as dificuldades e desafios de um arranjo institucional onde uma escola municipal coabita espaços de um equipamento público, gerenciado por uma Fundação, gerida pelo Governo do Estado.

Esse arranjo institucional apresenta contradições e tensões óbvias expostas no depoimento da professora 03 a respeito da relação "distante e burocrática" da gerência com os professores/as e as "provocações sutis" dos profissionais da CASE, em sua maioria, terceirizados da Fundação que prestam serviços na Unidade, quando fazem referência aos "privilégios" do corpo docente da escola municipal, compostos, majoritariamente, de 


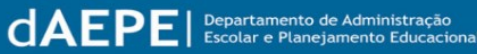

servidores/as estatutários/as.

É uma relação um pouco distante. Eu diria que temos uma relação burocrática. Você precisa gerir e eu preciso dar aula, não passa muito disso. Sobre as pessoas que trabalham na unidade é uma relação cordial. Às vezes ouço piadas, do tipo "fala com quem para trabalhar aí, para ser professor?" A gente sente uma certa ironia. (PROFESSORA 03)

A fala crítica da Professora 03 não é acompanhada pela professora 02, que pontua uma descrição mais otimista da integração da Gerência com a equipe escolar, destacando os avanços no tempo de atendimento escolar dos alunos e os comentários elogiosos do gerente sobre o trabalho da escola municipal.

Tem melhorado um pouco de uns anos para cá. É uma relação de respeito e trabalho. O Gerente disse que gostaria que a escola do estado fosse igual a escola municipal devido ao trabalho que a gente desenvolve aqui, do engajamento dos professores que levam a educação à frente [...] Melhorou a permanência dos alunos em sala por conta das questões da segurança. Há todo um trabalho para haver a aula em determinado horário, garantindo um atendimento individual para os alunos. (PROFESSORA 02)

A professora 01 apresenta uma descrição otimista da relação entre a Gerência da CASE e a Direção da Escola, apesar de se colocar no papel de observadora distante da realidade, o que nos leva a questionar as motivações dessa resposta ascética, provavelmente um esforço de não se comprometer com uma afirmação assertiva sobre o tema, "eu acredito que elas mantenham uma boa relação, nunca ouvi falar nada ao contrário. Eu acho que se faz um esforço para ter uma boa convivência" (PROFESSORA 01).

Apesar de pontuar a relação quase inexistente entre a Gerência da CASE com o Corpo docente da Escola, o que confirma a afirmação da relação direta do Gerente com o Diretor, a dinâmica do trabalho das equipes técnicas da Unidade converge com a descrição apontada no depoimento do Gerente sobre a articulação entre a educação formal (papel da escola) e o conjunto de atividades realizadas na CASE.

Eles vêm muito aqui, principalmente educador de medida, o educador de medida está sempre aqui na escola conversando sobre os alunos por ele acompanhados. Sempre que percebemos qualquer coisa diferente, na sala de aula, ou no comportamento do menino, recorremos a esse profissional. Essa relação melhorou bastante, as equipes técnicas vêm sempre na escola interagindo com a direção escolar e as professoras. (PROFESSORA 01) 
Em paralelo a essas relações institucionais potencialmente contraditórias, as afirmações das professoras, apontam uma sequência regular de reuniões para definir as ações pedagógicas das duas escolas, na sua dinâmica interna de relações interpessoais. Na escola 2 existe uma rotina de encontros individualizados semanais com a coordenadora pedagógica e um encontro quinzenal com todo o corpo docente.

Isso acontece muito mais entre eu e a coordenadora, temos uma reunião semanal onde conversamos sobre que eu estou fazendo e quais são meus próximos passos. Com a gestão da escola (direção e vice-direção) praticamente não existe isso. A coordenação é sempre mais participativa. (PROFESSOR 03)

Nós temos quinze em quinze um encontro com o grupo todo (gestão e professores) e de oito em oito, a gente tem o planejamento individual com a coordenadora pedagógica[...] Às vezes, a gente senta para discutir e depois marca um horário, para aprofundar outras informações, tudo é flexível. Para discutir o PPP e outros documentos marcamos uma reunião só para isso. Às vezes a reunião fica concentrada nos informes. (PROFESSORA 02)

As sutis diferenças entre as falas dos informantes apontam para uma maior ou menor afinidade desses profissionais com a equipe gestora. Sobre a dinâmica das reuniões coletivas e individualizadas a professora 03 pontua que "existe uma possibilidade de diálogo, de propor alguma coisa. Não é algo tão hermético, fechado. Existe espaço para proposição.” (PROFESSORA 03)

Ao responder ao questionamento sobre as reuniões de planejamento, a Professora 01 destaca as trocas diretas entre as profissionais do Corpo Docente, bem como a ação proativa das vice-diretoras no trato das questões pedagógicas além da contribuição dada pelo coordenador pedagógico encaminhado pela Secretaria de Educação.

O planejamento é feito em conjunto. A gente divide muito essa coisa, uma está contribuindo com o planejamento da outra, até porque o educando vai e volta. Hoje está comigo, precisou mudar de alojamento e passa para outra professora, porque ele vai estudar em outro turno. Por isso sempre compartilhamos informações sobre o nível de cada aluno, o planejamento é feito dessa forma. (PROFESSORA 01)

Nesses termos é possível inferir pelos depoimentos que as duas escolas possuem uma relação institucional com os setores das CASEs que - apesar das contradições aparentes indicam cumprir as expectativas anunciadas no marco legal em vigor para a educação formal 
de jovens cumprindo medida socioeducativa de internação.

\section{Questões de segurança}

Para atender a esse questionamento todos/as os/as profissionais vinculados à escola, professores/as e o/a diretor(a), e a CASE, socioeducadores e os gerentes, responderam perguntas relacionadas ao papel que a segurança exercia nas atividades pedagógicas e na gestão desenvolvidas nas Unidades Escolares. Apesar de todos os entrevistados confirmarem a relação direta entre a segurança da CASE e a dinâmica de funcionamento da Escola, existem nuances no consenso visível que caracterizam os diversos segmentos do trabalho socioeducativo contemplados nos/nas participantes das entrevistas.

A fala dos gerentes destaca a dimensão operacional, deslocamento dos adolescentes para o espaço escolar e o acompanhamento das aulas por um profissional de segurança, para viabilizar as atividades escolares.

Quando eu coloco todas as salas de aula para funcionar, eu preciso de um quantitativo de segurança, para que esse professor venha ministrar a sua aula. Tem momentos que a unidade pode estar em um quadro negativo de funcionários, que não vão funcionar todas as salas, mas isso não é costume. Graças a Deus a gente está com um quantitativo muito bom de colaboradores. Temos conseguido manter o funcionamento regular das aulas. (GERENTE 02)

Diferente da escola tradicional, no ambiente social comum, a escola do sistema socioeducativo, precisa atender algumas premissas e entre elas está a questão de criar um ambiente satisfatório para a segurança. Cabe a nós da unidade, da comunidade socioeducativa, a partir da relação com o nosso corpo de segurança, os socioeducadores criar esse ambiente promissor, para que a escola conduza os seus trabalhos da melhor forma possível. (GERENTE 01)

Os socioeducadores demarcam como sua principal atribuição garantir a integridade física dos adolescentes, intervindo diretamente em brigas por meio de procedimentos padrões de segurança sobre os adolescentes, revistas antes e depois da aula, para evitar desdobramentos mais sérios.

Para preservar uma vida nós temos que, às vezes, dizer um não ao professor, diminuindo o tempo de um projeto e limitando os materiais que ele vai usar nas atividades (SOCIOEDUCADOR 02). 
Os olhares atentos dos socioeducadores e sua presença nas salas de aula, no que pesem as situações fáticas de participação no processo educativo, cumprem o papel da vigilância no poder disciplinador sobre os "adolescentes internados", tanto para evitar reações adversas dos mesmos como para garantir a integridade desses corpos tutelados pelo Estado. Foucault (1999) se refere ao mecanismo da vigilância nesses espaços:

Fazer com que a vigilância seja permanente em seus efeitos, mesmo se é descontínua em sua ação; que a perfeição do poder tenda a tornar inútil a atualidade de seu exercício; que esse aparelho arquitetural seja uma máquina de criar e sustentar uma relação de poder independente daquele que o exerce; enfim, que os detentos se encontrem presos numa situação de poder de que eles mesmos são os portadores. Para isso, é ao mesmo tempo excessivo e muito pouco que o prisioneiro seja observado sem cessar por um vigia: muito pouco, pois o essencial é que ele se saiba vigiado; excessivo, porque ele não tem necessidade de sê-lo efetivamente. (FOUCAULT, 1999, pp. 224-225)

A presença dos socioeducadores é mencionada pela professora 03 que pontua a contribuição positiva e a intervenção de alguns desses profissionais acompanhando o percurso das aulas. Sua fala aponta para o avanço de relações que transcendem a lógica meramente instrumental do estrito exercício das funções desses profissionais que acompanham os adolescentes internados em plantões de 24 horas, ou em um expediente administrativo, avançando para dimensões educativas no cotidiano das aulas.

Não tem como fazer educação no socioeducativo sem o apoio da segurança, não tem condição. Eu vou dizer mais: quando tenho na minha sala um socioeducador que interfere na aula de forma positiva, isso melhora, inclusive, o processo pedagógico. Quando ele interfere de forma positiva, quanto ele ajuda, traz sua experiência ou algum conhecimento que ele tem daquele assunto e interfere de forma positiva é maravilhoso (PROFESSORA 03).

A fala da professora 01 destaca dois aspectos importantes: a realização de eventos da Unidade impacta diretamente na rotina de atendimento educacional e a CASE direciona um grupo fixo de socioeducadores que atua em horário administrativo para a escola municipal.

Influencia porque o primeiro ponto é a segurança que garante o funcionamento da escola. Se tiverem cinco salas funcionando, precisamos de seis socioeducadores. Um para cada sala e um para a posição do banheiro. Se acontecer qualquer problema, de um adoecer, de um 
imprevisto uma sala não funciona. (PROFESSORA 01).

Como foi destacado nas falas dos Gerentes, para garantir o funcionamento da escola é necessário cumprir a logística de segurança que vai do deslocamento dos adolescentes até o acompanhamento da aula por um ou mais socioeducadores. Dessa forma a realização de eventos coletivos das CASEs dificulta o expediente pedagógico da Escola. Assim, na maioria das vezes, a equipe escolar participa das atividades que contemplam boa parte dos alunos da Escola Municipal.

Sobre o tema, os diretores 01 e 02 acompanham o consenso geral sobre a influência direta da segurança sobre a dinâmica das atividades escolares. O diretor 01 pontua os esforços realizados pela sua gestão com o objetivo de garantir a presença dos socioeducadores nas salas, para que as brigas no espaço da escola não serem uma realidade constante. $\mathrm{O}$ diretor 02 destaca a articulação da Escola com os profissionais de segurança, além dos esforços da gestão e da equipe escolar para mitigar os efeitos de eventuais suspensões totais ou parciais das aulas.

Apesar das dificuldades anunciadas pelos/as informantes foi possível inferir esforços aparentes dos/das profissionais envolvidos/as na educação formal dos adolescentes internados nas duas CASEs em reduzir os impactos negativos da dinâmica de segurança sobre o Direito a Educação desses alunos/as.

\section{Relação entre os professores/as e os alunos}

Um aspecto que dialoga diretamente com as questões de segurança e o trabalho com a educação formal nas duas escolas é a relação dos alunos com os/as professores/as. Sobre isso, as professoras foram unânimes ao afirmar que as relações entre o corpo docente e o alunado são boas, sendo os vínculos pessoais e afetivos uma ferramenta para a permanência dos alunos em sala de aula.

De uma forma geral, eu considero uma boa relação. Eu vejo que os professores procuram fazer o melhor que cada um pode fazer, dentro de um ambiente que a gente tem que lutar contra a falta de recurso para trabalhar e ainda a falta de consciência dos próprios alunos da importância da escola. A maioria deles não vê sentido e nem importância na escola 
então, você tem que entrar na sala de aula, normalmente, e lutar contra o próprio desestimulo que vem do seu aluno. (PROFESSORA 03)

Uma relação boa é naquela questão de que no socioeducativo a gente não tem como escolher os alunos, não tem como olhar para o aluno e fechar os olhos ou dar as costas. A gente trabalha com esses educandos de uma forma que valoriza o que ele já traz de conhecimento... porque são jovens que necessitam desse olhar. (PROFESSORA 02)

A fala da Professora 01 pontua a necessidade de respeitar as trajetórias de vida dos adolescentes, que compensam a pouca idade com experiências vivas que eventualmente ascendem nas atividades desenvolvidas em sala de aula, e as práticas de colaboração e acolhimento entre as professoras mais experientes e as recém-chegadas nessa realidade educacional tão singular.

Uma relação boa. Eu digo assim: quem vai chegando, a gente vai sempre falando do respeito com o educando porque ele já viveu muito, embora tenha pouca idade. Tem muita experiência, muita vivência de rua, de tudo e vem com tudo muito definido. Então é tudo uma conquista, de que forma você vai conquistar a presença dele em sala de aula, de que forma você vai estimular o interesse dele e manter uma boa relação com todos eles. (PROFESSORA 01)

Nesses termos é possível observar que os depoimentos aproximam as práticas dos/das professores/as das duas escolas aos referenciais pedagógicos da FUNDAC, a pedagogia da presença, sistematizada por Costa (1997)

Fazer-se presença construtiva na vida de um adolescente em dificuldade pessoal e social. Esta é pois, a primeira e a mais primordial das tarefas de um educador que aspire assumir um papel realmente emancipador na existência de seus educandos. (COSTA, p.27)

Cumpre ressaltar no que diz respeito à importância da escola dada por esses colaboradores, que as suas falas vão ao encontro de considerar este a escola inserida numa instituição socioeducativa como fundamental para o processo de formação dos adolescentes em regime de privação de liberdade, mesmo que nos seus depoimentos não fique bem delimitada a articulação necessária entre as escolas aí existentes com os outros setores e serviços das instituições. 


\section{Considerações finais}

Ao analisar o papel da Escola em Unidades de Atendimento Socioeducativo de Internação é preciso conformar os caminhos específicos desses espaços, delimitando os contornos para aferir o cumprimento, ou não, do marco legal. A negação do acesso ao direito à educação por se tratar de espaços de privação da liberdade vai na contramão dos pressupostos anunciados na Ordem constitucional de 1988 e toda a legislação que protege as crianças e adolescentes.

As entrevistas apontam para a (re)produção de estigmas criminalizantes sobre os jovens tutelados nas Unidades de Internação e matriculados nas escolas municipais, mas emergem iniciativas de diálogo horizontal entre professores/as e o alunado. Além dos entraves legais, limite levantado como hipótese da pesquisa, foi observado nos dados do campo que existem mecanismos ideológicos que influenciam na construção de sentidos dos sujeitos inseridos nas unidades de internação. A ação desse duplo Aparelho Ideológico do Estado (Escola/Prisão) projeta sobre os/as profissionais construções ideológicas que fazem com que a realidade seja aceita como algo dado, sem um horizonte real de ruptura. A docilidade dos corpos aprisionados é incorporada, em parte, pelos/as colaboradores da pesquisa e por extensão aos profissionais engajados nas Unidades de Internação.

É esperada que a tutela do Estado sobre os/as adolescentes em Unidades de Internação e o contexto de privação da liberdade, no que pese a legislação conformar um horizonte pedagógico às medidas socioeducativas, imponha adequações ao Direito a Educação. Desse modo, antes da análise das informações extraídas do campo foram delimitadas as concepções educativas e criminológicas presentes nas falas dos/das entrevistados/das, em paralelo a necessária genealogia dos projetos pedagógicos e/ou criminalizantes presentes na tutela do Estado sobre "as juventudes em conflito com a lei".

Essas Juventudes são "emparedadas" pela seletividade de um Estado penal que projeta para os segmentos pauperizados os espaços de privação de liberdade (prisional/socioeducativo) como desdobramento de um projeto articulado de desumanização pautado na negação dos direitos sociais e coletivos. 
A realidade singular das duas escolas municipais inseridas em Comunidades de Atendimento Socioeducativo de Internação (CASE) aponta dilemas institucionais únicos, onde um equipamento público do município está inserido em um espaço de privação de liberdade gerenciado pelo Governo do Estado. Essa complexa rede de atribuições de entes federados, com profissionais de vínculos de diversas naturezas (estatutários/ temporários/Cargos Comissionados/Terceirizados) convive mediante tensões e conflitos no atendimento socioeducativo.

As entrevistas demarcam que as dificuldades são superadas pelo compromisso e esforço coletivo dos profissionais engajados com a educação formal, bem como os diversos setores das duas CASEs. Assim, mesmo com o evidente impacto das questões de segurança na dinâmica educativa das duas escolas é possível inferir nas falas uma tentativa de articular as ações vinculadas à escolarização e o trabalho da equipe de segurança, tanto para garantir um maior tempo de contato com as aulas, como para mitigar os efeitos de suspensões parciais ou totais das atividades pedagógicas no espaço escolar.

Dessa maneira, foi observada nos depoimentos uma relação dialógica e propositiva na relação entre os/as professores/as e os alunos, bem como possibilidades cotidianas de atuação dos socioeducadores que transcendam as questões de segurança e alcancem uma função eminentemente educativa em uma aproximação evidente com os princípios anunciados pela FUNDAC. Essa constatação vai de encontro ao formato prescrito para esse Aparelho Ideológico Híbrido (Escola/Prisão) e dos mecanismos de controle/poder disciplinar sobre "corpos-dóceis" estabelecidos nas duas unidades de internação, mostrando que os modelos explicativos devem se adequar a realidade concreta, não o contrário.

\section{Referências}

ALTHUSSER, L. Aparelhos Ideológicos de Estado: nota sobre os aparelhos ideológicos do Estado. 2.ed. Tradução: Walter José Evangelista e Maria Laura Viveiros de Castro. Introdução crítica José Augusto Guilhon Albuquerque, Rio de Janeiro: Edições Graal, 1985.

BARDIN, L. Análise de Conteúdo. Tradução: Luís Antero Reto, Augusto Pinheiro. São Paulo: Edições 70, 2016. 
BORGES, J. O que é encarceramento de massas? Belo Horizonte/MG: Letramento: Justificando, 2018

BRASIL. Constituição da República Federativa do Brasil. 1988. Disponível em: http://www.planalto.gov.br/ccivil_03/constituição/constituição.htm. Acesso em: $12 \mathrm{dez}$. 2018.

Lei de Diretrizes e bases da Educação Nacional, Lei 9394, 20 dez. 1996. Estabelece as diretrizes e bases para educação nacional. Brasília. Disponível em: http://www.planalto.gov.br/ccivil_03/constituição/constituição.htm. Acesso em 12 dez. 2018.

Lei 12.594, de 18 de janeiro de 2012. Institui o Sistema Nacional de Atendimento Socioeducativo (SINASE). Diário Oficial da União, Brasília, 18 jan. 2012.

BRASIL. Ministério dos Direitos Humanos. Levantamento Anual SINASE 2016 Brasília; 2018. Disponível em: http://www.mdh.gov.br/assuntos/criancas-eadolescentes/programas/sistema-nacional-de-medidas-

socioeducativas/Levantamento_2016.pdf. Acesso em: 27 abr. 19

COSTA, A. C. G. da. Pedagogia da presença: da solidão ao encontro. Belo Horizonte: Modus Faciendi, 1997. 140p

CRAIDY, C. M.; SZUCHMAN. K. Socioeducação: fundamentos e práticas. Porto Alegre: Editora da UFRGS, 2017.

DAVIS, A. Estarão as prisões obsoletas? Rio de Janeiro: Difel, 2018.

FLAUZINA, A. L. P. Corpo negro caído no chão: o sistema penal e o projeto genocida do Estado brasileiro. 2. ed. Brasília: Brado Negro, 2017.

GONTIJO, D. R. Medidas socioeducativas de privação de liberdade no Brasil: uma revisão sistemática de literatura. 2019.

GRAMSCI, A. Os Intelectuais e a Organização da Cultura, Rio de Janeiro: Civilização Brasileira, 1968

FOUCAULT, M. Vigiar e punir: nascimento da prisão. 20.ed. Tradução: Raquel Ramalhete. Petrópolis: Vozes, 1999.

IBGE. Síntese dos Indicadores Sociais: uma análise das condições de vida da população brasileira: 2016. 146f. Rio de Janeiro: IBGE, 2016. Disponível em: https://biblioteca.ibge.gov.br/visualizacao/livros/liv98965.pdf. Acesso em: 19 mai. 2019.

RIZZINO; SPOSATI; OLIVEIRA. Adolescências, direitos e medidas socioeducativas em 


\section{REVISTA DE ADMINISTRAÇÃO EDUCACIONAL}

\section{ISSN -2359-1382}

dAEPE|

meio aberto. São Paulo: Cortez Editora, 2019.

OLIVEIRA, M. C. L.; VALENTE, F. P. R. Adolescência e responsabilização socioeducativa: aspectos históricos, filosóficos e éticos. In: ZAMORA, M. H.; VOLPI, M. O adolescente e o ato infracional. 9. ed. São Paulo: Cortez, 2011.

Recebido em: 20/07/2021

Aceito em: 30/09/2021

Revista Administração Educacional - CE - UFPE Recife-PE, V.12 N. 2 p.271-288, jul/dez 2021 